\title{
Molecular Flexibility Operated Mesomorphism
}

\author{
Rajesh B. Marathe ${ }^{1}$, N. N. Vyas ${ }^{2}$, Doshi A. V. ${ }^{3}$ \\ ${ }^{1}$ Huntsman International India Pvt. Ltd, Umraya village, Taluka: Padra, Vadodara-391 440, Gujarat, \\ India, Dr. K.N. Modi University, Newai, Dist. Tonk, Rajasthan-304021 \\ ${ }^{2}$ P.T. Arts and Science College, Godhara \\ ${ }^{3}$ Dr. K.N. Modi University, Newai, Dist. Tonk, Rajasthan-304021 \\ E-mail address: maratha79raj@gmail.com
}

Keywords: Mesomorphism; Nematic; enantiotropy; Liquid Crystal; Smectic

\begin{abstract}
Novel homologous series: RO- $\mathrm{C}_{6} \mathrm{H}_{4}-\mathrm{CH}=\mathrm{CH}-\mathrm{COO}-\mathrm{CH}_{2}-\mathrm{C}_{6} \mathrm{H}_{4}-\mathrm{Br}$ (p) synthesized and studied with a view to understand and establish the effects of molecular structure on liquid crystal (LC) behavior of a series. Series consists of eleven homologues. $C_{1}$ to $C_{7}$ members of a novel series are non-liquid crystals. Mesomorphism commences from Octyloxy $\left(\mathrm{C}_{8}\right)$ homologue and continued upto hexadecyloxy homologue $\left(\mathrm{C}_{16}\right)$ as enantiotropic nematic without exhibition of smectic property. The textures of a nematic phase are threaded or Schlieren. Transition temperatures (table-3) and textures are determined by an optical polarizing microscopy equipped with a heating stage. Cr-N/I and N-I transition curve behaved in normal manner in phase diagram, showing their phase behavior (figure-2). Odd-even effect is absent for N-I transition curve. Analytical and spectral data confirmed the molecular structures of a series. The LC properties are compared with the structurally similar series. The transition temperatures are relatively lower than the corresponding n-alkoxy benzoic acid. Thus, present novel series is partly nematogenic with absence of smectic property whose mesogenic phase length is low and of low ordered melting type. Thermal stability for nematic is $93.0^{\circ} \mathrm{C}$ and the mesophaselength ranges from 8 to $21^{\circ} \mathrm{C}$.
\end{abstract}

\section{INTRODUCTION}

Liquid crystalline (LC) state [1] of substance is an intermediate state of existence between crystalline solid and isotropic liquid, which is partly crystalline and partly liquidous, flowing as liquid on the surface but possess an optical property as crystal. Exploiting such abnormal behaviours, it has number of applications in the benefit of mankind as to manufacture LC devices and proven its ability in the biological systems [2-8]. Present investigation is planned with a view to understand and establish the effects of molecular structure on LC properties [9-12] with references to the molecular flexibility, keeping molecular rigidity unaltered for the all homologues of a homologous series. Therefore, novel LC substances will be generated as the alternative source of LC materials, useful to the group of scientific research community specifically working in the application part and it will enhance the knowledge of constructing LC materials workable as per our desire and need. Number of homologous series have been reported till the date [13-21] with ester, central or terminal group. Thus, novel ester series with three phenyl rings and two central bridges $-\mathrm{COO}-$ and $-\mathrm{CH}=\mathrm{CH}-\mathrm{COO}-\mathrm{CH}_{2}$ - will be synthesized, characterized and its thermometric evaluated data will be interpreted and compared with structurally similar series on the basis of molecular rigidity and flexibility [22-25]. Comparative study will help to understand and establish the effects of molecular structure on mesomorphic properties.

\section{EXPERIMENTAL}

4-Hydroxy benzoic acid, Alkyl halides, Methanol, KOH, 4-bromo benzyl bromide or alcohol, N,N-Dimethyl Formamide, NaHCO3, HCl, Dry Pyridine, Thionyl chloride, EtOH etc required for the synthesis were used as received, except solvents which were dried and purified prior to synthesis. 


\subsection{General method for the preparation of n-alkoxy benzoic acid and 4-Hydroxy-4- bromobenzyl cinnamate.}

4-Hydroxy benzoic acid was alkylated by suitable alkylating agent R-X to form n-alkoxy benzoic acid by modified method of Dave and Vora [26] as main component of a series. 4Hydroxy-4'-bromobenzyl cinnamate (m.p:95-96 ${ }^{\circ} \mathrm{C}$ ) was prepared from 4-bromo benzyl bromide or alcohol and 4-Hydroxy Cinnamic acid by applying the method of European patent and the modified method of Doshi, Patel and Marathe [27].

\subsection{General method for the preparation of final esterified products.}

The n-alkoxy benzoic acid through their corresponding acid chlorides and 4-Hydroxy-4'bromobenzyl cinnamate were condensed in dry cold Pyridine to form final products by usual established method [28]. Final esterified products were individually decomposed, filtered, washed, dried and purified till their constant transition temperatures obtained. Synthetic route to the series is mentioned below as scheme-1.
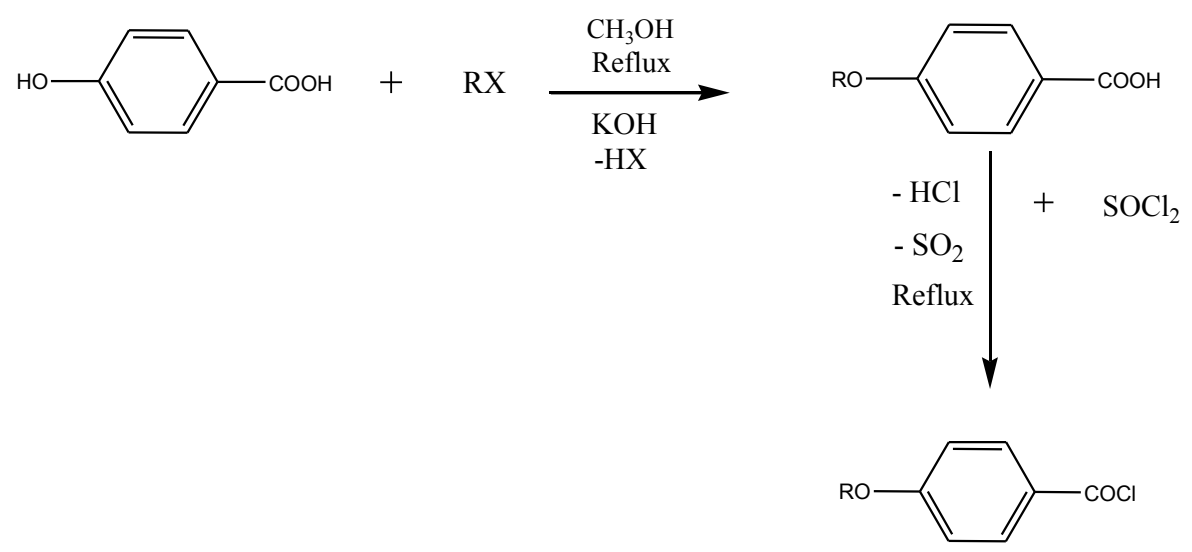

A
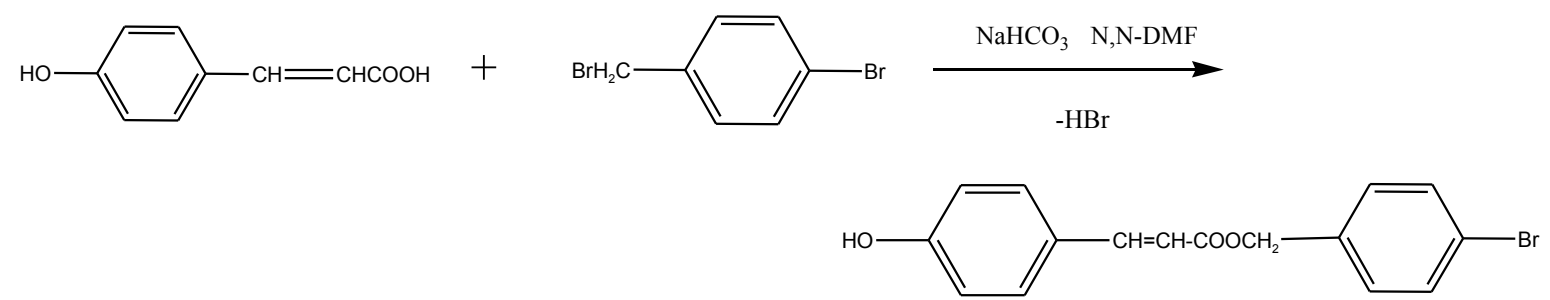

B

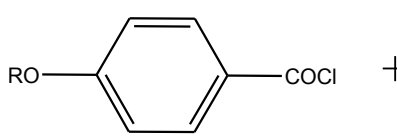

A
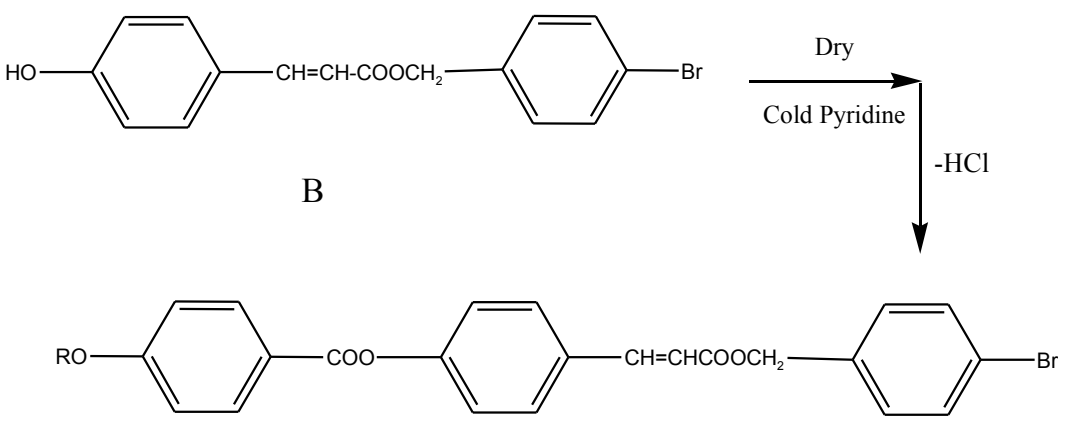

Final 


\section{CHARACTERIZATION}

The selected members of a novel homologues series were characterized and analyzed by elemental analysis and the structure elucidation by Infra-red spectra, ${ }^{1} \mathrm{HNMR}$ spectra and mass spectra. Textures and Transition temperatures of homologues as well as of related materials were determined by an optical polarizing microscope, equipped with a heating stage. Elemental analysis was performed on Perkin-Elemer PE $2400 \mathrm{C}, \mathrm{H}, \mathrm{N}$ analyzer. The percentage halide content is determined by usual analytical method. IR spectra were recorded on Shimadzu FTIR ModelIRAffinity-1S (MIRacle 10). 1HNMR spectra were determined on Bruker spectrometer using CDCl3 solvent and mass spectra were recorded on Shimadzu GC-MS Model No.QP-2010. Textures of nematic mesophase of some homologues were recognized either directly from the microscopic observations or by miscibility method.

\section{ANALYTICAL DATA}

Table-1: Elemental analysis for (1) Ethoxy (2) Propyloxy and (3) Hexyloxy derivative

\begin{tabular}{|c|c|c|c|c|}
\hline \multirow{2}{*}{ Sr.No. } & \multirow{2}{*}{ Molecular formula } & \multicolumn{3}{|c|}{ \% Elements calculated (Experimental \%) } \\
\cline { 3 - 5 } & & $\mathrm{C}$ & $\mathrm{H}$ & $\mathrm{Br}$ \\
\hline 1 & $\mathrm{C}_{25} \mathrm{H}_{21} \mathrm{BrO}_{5}$ & $62.37(65.22)$ & $4.36(4.80)$ & $16.63(16.48)$ \\
\hline 2 & $\mathrm{C}_{26} \mathrm{H}_{24} \mathrm{BrO}_{5}$ & $62.90(63.20)$ & $4.83(4.78)$ & $16.12(16.50)$ \\
\hline 3 & $\mathrm{C}_{29} \mathrm{H}_{29} \mathrm{BrO}_{5}$ & $64.80(64.80)$ & $5.50(5.40)$ & $14.78(14.89)$ \\
\hline
\end{tabular}

\section{Spectral Data:}

\section{${ }^{1}$ HNMR data for series}

${ }^{1} H N M R$ in ppm for the Methoxy Derivative: 1.07-1.19 $\left(-\mathrm{CH}_{3}\right.$ groups $), 2.66\left(-\mathrm{CH}_{3}\right), 5.13-5.27$ (-CH=CH-), 6.90-6.92 (p-substituted phenyl ring), 7.85-7.91 (p-substituted benzene).

${ }^{1} H N M R$ in ppm for the Dodecyloxy Derivative: 0.86-88 $\left(-\mathrm{CH}_{3}\right.$ of $\left.\mathrm{C}_{12} \mathrm{H}_{25}\right), 1.24-1.77\left(-\mathrm{CH}_{2}-\right.$ of $\mathrm{C}_{12} \mathrm{H}_{25}$ ), 3.97-3.99 (-O- $\left.\mathrm{CH}_{2-}\right)$, 5.16-5.30 (-CH=CH-), 6.90-6.93 (p-substituted phenyl ring), 7.307.40 (p-substituted benzene).

NMR data confirm the structure.

\section{IR in $\mathbf{~ c m}^{-1}$ for Butyloxy Derivative}

2954, 2870 (C-H str.), 1465 (str. of (- $\left.\mathrm{CH}_{2}-\right)$ group of $\left.-\mathrm{OC}_{4} \mathrm{H}_{9}\right), 1675$ (-COO- ester group), 1604 (C$\mathrm{H}$ stretching of $-\mathrm{CH}=\mathrm{CH}-), 1512(\mathrm{C}=\mathrm{C}$ str. of alkene), $1396(\mathrm{C}-\mathrm{H}$ bending of alkene disubstituted), 1257 (C-O str. of ether linkage), 1165 (C-O str. of ester group), 1016 (Aromatic linkage of -Br), 848 (para substituted phenyl ring), 771 (Polymethylene group), 640-695 ( $-\mathrm{CH}_{2}$ Stretch). The IR data are consistent with the molecular structure.

IR in $\mathbf{~ c m}^{-1}$ for Pentyloxy Derivative

2931, 2870 (C-H str.), 1489 (str. of (- $\mathrm{CH}_{2}$ ) group of $\left.-\mathrm{OC}_{5} \mathrm{H}_{11}\right), 1597$ (-COO- ester group), 1712 (C-H stretching of $-\mathrm{CH}=\mathrm{CH}-), 1512(\mathrm{C}=\mathrm{C}$ str. of alkene), $1396(\mathrm{C}-\mathrm{H}$ bending of alkene), $1257(\mathrm{C}$ $\mathrm{O}$ str. of ether linkage), 1165 (C-O str. of ester group), 1010 (Aromatic linkage of -Br), 848 (para substituted phenyl ring), 756 (Polymethylene group), 648-689 (- $\left.\mathrm{CH}_{2}-\mathrm{Stretch}\right)$. The IR data are consistent with the molecular structure.

Mass spectra of Tetradecyloxy Derivative

Theoratical Mass $=649.0$

Experimental Mass $=\mathbf{6 4 9 . 8 0}$

\section{RESULT AND DISCUSSION}

LC homologues or non-liquid crystal homologues excluding Octyloxy and onward $\left(\mathrm{C}_{8}\right.$ to $\left.\mathrm{C}_{16}\right)$ novel homologues are the derivatives of dimeric 4-n-alkoxy benzoic acids. The transition temperatures of novel homologues are lower than corresponding to 4-n-alkoxy benzoic acids. 
Enantiotropic nematic phase commences late from $\mathrm{C}_{8}$ homologue of a series, with absence of smectogenic character. Numbers of carbon atoms of n-alkyl chain are plotted versus the transition temperatures of left n-alkoxy polar end group. Like or related points are linked to form Cr-N/I and N-I transition curves, showing phase behaviours of series in a phase diagram (figure-2). Odd-even effect is absent for N-I transition curve. The analytical and spectral data confirmed the molecular structures of homologues. The changing Thermometric behaviours from homologue to homologue in a series varied keeping right sided tail end group intact throughout the novel series. Negligible abnormal behaviour is attributed to more polarizable $-\mathrm{Br}$ end group and the effect of unexpected status of longer n-alkyl chain linked with first phenyl ring through oxygen atom. Thus, present series is partly nematogenic without exhibition of smectic property whose mesophaselength is relatively shorter, low thermal stability $\left(93.0^{\circ} \mathrm{C}\right)$ and lower ordered melting type.

The disappearance of dimerization of 4-n-alkoxy benzoic acids and the lowering of transition temperatures of present homologues are attributed to the breaking of hydrogen bonding between two molecules of aromatic acids by esterification process. The exhibition of only nematic phase from $\mathrm{C}_{8}$ homologue attributed to the commencement of suitable magnitudes of anisotropic forces of end to end intermolecular attractions, which causes an environmental situation of floating molecules to float on the surface with statistically parallel orientational order with restricted magnitudes of entropy $(\Delta S=\Delta H / T)$, within definite range of temperature. However, the intermolecular attractions are failed to build up lamellar packing of molecules to cause sliding layered arrangement to induce smectic mesophase formation. Thus, absence of smectogenic character and exhibition of only nematic property is facilitated under the influence of exposed thermal vibration late from $\mathrm{C}_{8}$ homologue. The early homologues, prior to commencement of nematogenic mesophase are abruptly breaking their crystal lattices and sharply transform directly from solid crystal lattices to isotropic liquid without passing through LC state due to their high crystallizing tendency which arises from their inability to resist exposed thermal vibrations as a consequence of unfavourable magnitudes of combined effect of molecular rigidity and flexibility induced by low dipole-dipole interactions and the low magnitudes of dispersion forces through interactions between instantaneous dipole produced by the spontaneous oscillations of electron clouds of the molecules. All the molecules of mesomorphic homologues on heating above the isotropic temperatures randomly orient in all possible directions with high order of disorder or with high order of unrestricted entropy. But, on cooling the same, a reversible nematic mesophase reappears from and below isotropic temperature till it solidify to crystalline state. The absence of odd-even effect in N-I transition curve is due the unsuitable magnitudes of anisotropic forces of intermolecular end to end attractions which produced by the homologues of shorter n-alkyl chain of left n-alkoxy terminal end group. Negligible abnormality in N-I transition curve for $\mathrm{C}_{14}$ homologue is attributed to its unusual status of longer nalkyl chain. The changing trends in LC properties from homologue to homologue in the present novel series is attributed to the changing number of methylene unit or units of n-alkyl chain, keeping the rest of the molecular part unchanged throughout the novel series under discussion. Some LC properties of present series-1 are compared with the structurally similar homologous series-X [29] and Y [30] as under in figure-1.

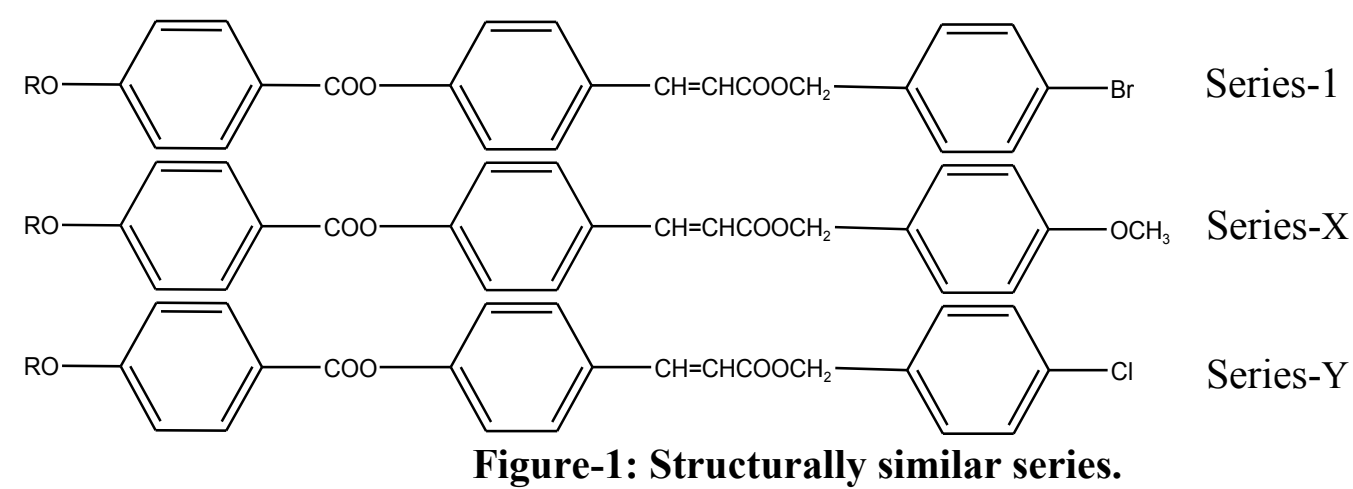


Homologous series-1, $\mathrm{X}$ and $\mathrm{Y}$ are identical with respect to three phenyl rings and two central bridges $-\mathrm{COO}$ - and $-\mathrm{CH}=\mathrm{CH}-\mathrm{COO}-\mathrm{CH} 2-$ which contributes to the total molecular rigidity. They are also identical with respect to n-alkoxy (-OR) terminal end groups for the same homologue from series to series. However, series-1, $\mathrm{X}$ and $\mathrm{Y}$ differ with respect to tail end groups $-\mathrm{Br},-\mathrm{OCH}_{3}$ and $\mathrm{Cl}$ which contributed to the total molecular flexibility from homologue to homologue in the same series and for the same homologue from series to series. Thus, the variations in mesomorphic (LC) properties and the degree of mesomorphism will depend upon the differing features and their magnitudes of combined effects of total molecular rigidity and flexibility. Following table-2 represent some LC properties of series-1, X and Y under comparative study.

Table-2: Relative thermal stability in ${ }^{\circ} \mathrm{C}$

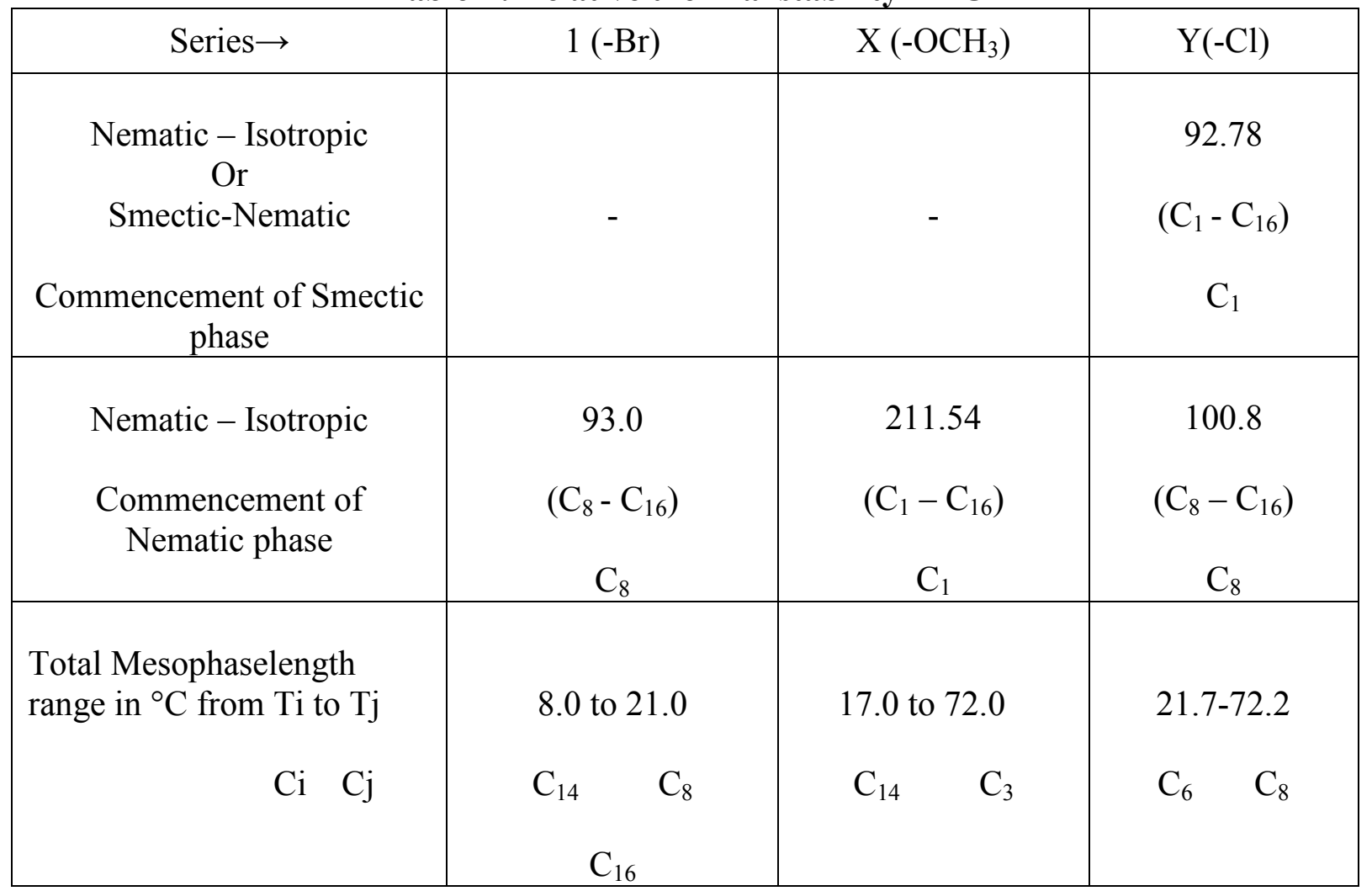

Table-2 indicates that,

- Homologous series-1 and $X$ are only nematogenic whereas series-Y is smectogenic in addition to nematogenic.

- Smectic mesophase commences from very first member of a series-Y, but it does not commence till the last member of the series- 1 and $\mathrm{X}$.

- Nematic mesophase commences from very first member of a series-X, but it commences late from $\mathrm{C}_{8}$ membered homologue for series- 1 and $\mathrm{Y}$.

- Nematic thermal stabilities are in increasing order from series-1 to series-Y to series-X.

- Smectic thermal stability of series-Y is 92.78 but smectogenic mesophase did not stabilize for series-1 and $\mathrm{X}$.

- Total mesophaselength ranges are varied in decreasing order from series- $\mathrm{X}$ to series- $\mathrm{Y}$ and series-1.

Variations in the mesogenic behaviours of the series under comparison are attributed to the magnitudes of molecular flexibility arising from changing tail end groups $-\mathrm{Br},-\mathrm{OCH}_{3}$ and $-\mathrm{Cl}$, whose individual group polarities group atomicity, inductive effect, effects due to molecular length to breadth ratio, ratio of the polarity to polarizability, permanent dipole moment across the long molecular axes, dipole-dipole and electronic interactions. $\mathrm{C}-\mathrm{Xi}$ (where $\mathrm{Xi}=$ terminal tail group) 
bond polarity, dispersion forces, Vander Waals forces, the suitable magnitudes of anisotropic forces of intermolecular attractions as a consequence of varied molecular flexibility for the same homologue from series to series and from homologue to homologue in the same series etc; show variations in the mesogenic behaviours from series- 1 to series-X to series-Y. Mono atomic $-\mathrm{Cl}$ tail end group of series-Y is more efficient and capable to build up lamellar packing of molecules in the crystal lattices as compared to $-\mathrm{OCH} 3$ and $-\mathrm{Br}$ terminal ends of greater size, which maintained sliding layered molecular arrangement for series-Y but fails to maintain the same for - $\mathrm{OCH} 3$ and $\mathrm{Br}$ of series- 1 and $\mathrm{X}$ to facilitate smectic mesophase formation. The formation of nematic mesophase of low thermal stability by $-\mathrm{Br}$ and $-\mathrm{Cl}$ terminal end groups is attributed to their low dipolarity of $\mathrm{C}-\mathrm{Xi}$ bond but, - $\mathrm{OCH} 3$ terminal end group being highly polar and polarizable as compared to $-\mathrm{Br}$ and $-\mathrm{Cl}$ enhances nematic thermal stability more than halogen $\mathrm{C}-\mathrm{Xi}$ substituent. Thus, resistivity towards exposed thermal vibrations being comparatively more for the series involving - $\mathrm{OCH} 3$ tail group stabilizes and facilitates nematic mesophase formation at the cost smectic phase with highest degree of mesomorphism.

\section{CONCLUSIONS}

- Presently investigated novel series is partly nematogenic without exhibition of smectogenic character of low melting and short degree of mesomorphism.

- Group efficiency order derived for smectic and nematic on the basis of (i) thermal stability (ii) early commencement of mesophase (iii) the total mesophaselength.

(i) Smectic<smiles>COC#C[C@H](Cl)C(Cl)Cl</smiles>

$\underline{\text { Nematic }}$

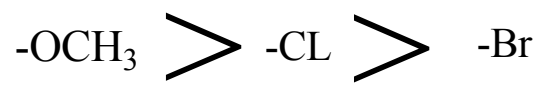

(ii) Smectic<smiles>COC#C[C@H](Cl)C(Cl)Cl</smiles>

$\underline{\text { Nematic }}$<smiles>CC(C)C(Cl)C#CBr</smiles>

(iii) $(\mathrm{Sm}+\mathrm{N})$ Total Mesophaselength

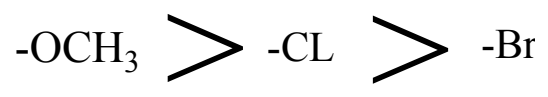

- Present investigation may be useful for the study of binary system for LC devices workable between $57^{\circ} \mathrm{C}$ and $90^{\circ} \mathrm{C}$.

- Present novel compounds may be useful as fire resistance material.

- Thus, present investigation supports the conclusions drawn earlier and raises the credibility to the existing literature on LC. 
Table-3: Transition temperatures in ${ }^{\circ} \mathrm{C}$

\begin{tabular}{|c|c|c|c|c|}
\hline $\begin{array}{c}\text { Compound } \\
\text { No. }\end{array}$ & $\begin{array}{c}\text { n-alkyl chain } \\
\mathbf{C}_{\mathbf{n}} \mathbf{H}_{\mathbf{2}+\mathbf{1}}(\mathbf{n})\end{array}$ & Sm & N & Isotropic \\
\hline 1 & 1 & - & - & 94 \\
\hline 2 & 2 & - & - & 103 \\
\hline 3 & 3 & - & - & 92 \\
\hline 4 & 4 & - & - & 89 \\
\hline 5 & 5 & - & - & 85 \\
\hline 6 & 6 & - & - & 87 \\
\hline 8 & 8 & - & 77 & 98 \\
\hline 9 & 10 & - & 79 & 91 \\
\hline 10 & 12 & - & 77 & 93 \\
\hline 11 & 14 & - & 89 & 97 \\
\hline 12 & 16 & - & 78 & 86 \\
\hline
\end{tabular}

Sm- Smectic; N- Nematic

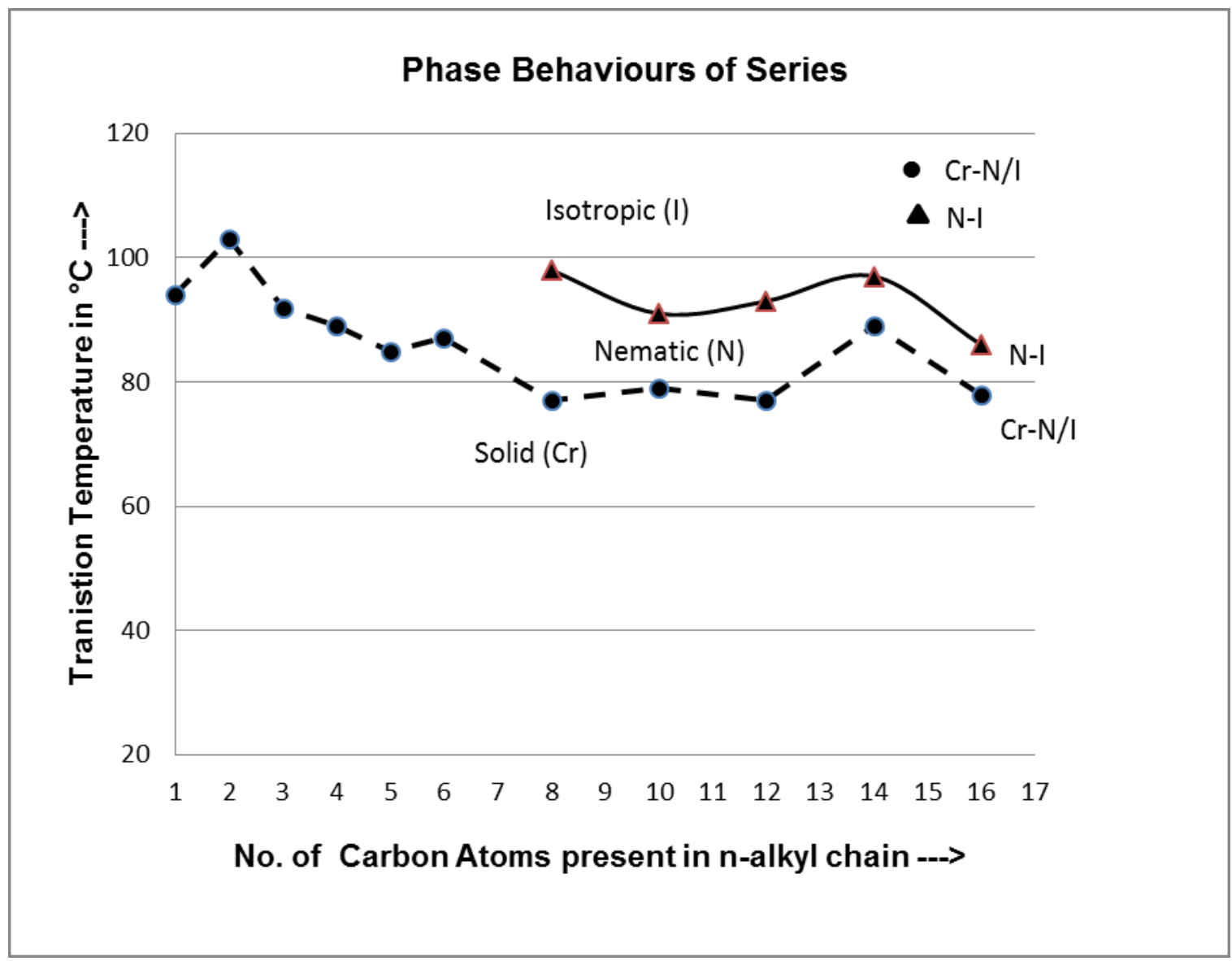

Figure-2: Phase Behavior of Series

\section{Acknowledgements}

Authors acknowledge thanks to the Green Circle Inc. Laboratory for providing research facilities services as and when needed. Authors acknowledge thanks to the Mr. Baldev Prajapati of Rajesh Pharma Ankleshwar, for providing the free sample of 4-Bromobenzyl bromide. Authors are also thankful to Dr.Vipul Patel and Dr. M.L.Chauhan, P.T. Arts and Science College, Godhara, for their valuable helping hand and microscopic facility. Also thanks are due to the Sophisticated Analytical Instrumentation Facility, Punjab University, (Chandigarh) for extending their help for analytical services. 


\section{Reference:}

[1] F. Reinitzer, Monatsh 9, 421 (1888)

[2] Naemura, S. (2001). Advance LCD technologies, Displays, 22 (1), 1.

[3] W.S. Kim, Elston, S.J., \& Raynes, F.P. (2008). Display, 29, 458-463.

[4] ImaranTadwee, Dr. Sahanashahi, Vivek Ramteke, Iftequar Syed, Liquid Crystals pharmaceutical Application: A review, IJPRAS, ISSN 2277-36. Vol. 1, Issue 2 (2012), 06-11.

[5] E.Hertz, B.Lavorel and O.Faucher, Optical imagin by molecular gas, Nature photon; 5 (2011) PP. 783.

[6] G.W. Gray and P.A. Winsor (Eds) Liquid Crystals and plastic crystals, chapter-6.2, The role of liquid crystal in life processes by G.T. Stewart, Vol-1, PP. 308-326.

[7] G. Rajesh, K. Mansi, K. Srikant, B. Babasaheb, D. Nagesh, S.Kavita, C. Ajay, Chem. Pharm. Bull, 2008, 56, PP. 897-901.

[8] Prajkata P.Gaikwad, Maya T.Desai, “ Liquid crystalline phase and its Pharma application" International journal of Pharma Research and Review, Dec.2013; 2 (12) : 40-52.

[9] G.W. Gray (1974) In; G.W. Gray and P.A Winsor (eds) liquid crystals and plastic crystals, Chapter-4, Volume-1, PP-103-153.

[10] G. W. Gray, Molecular structures and properties of liquid crystals, Academic press, Landon, 1962.

[11] G.W. Gray and B. Jones, Mesomorphism and chemical constitution part-3, The effect of halogen substitution on the 4-Alkoxy benzoic acids. Journal of chemical society (1954), PP. 2556-2562.

[12] C. T. Imrie, Liq. Crystal dimers. Struct. Bond 95 (1999) PP. 149-192.

[13] D.Demus, 100 years of liquid crystal chemistry, mol.cryst. liq.cryst. 165 (1988) PP.45-84.

[14] D. Demus, Plenary lectures 100 years of liquid crystals chemistry, Thermotropic liquid crystals with conventional and unconventional molecular structures, Liq.Cryst, 5 (1988). PP. $75-110$

[15] D. Demus, Plenary lectures 100 years of liquid crystals chemistry, Thermotropic liquid crystals with conventional and unconventional molecular structures, Liq.Cryst, 5 (1988). PP. $75-110$

[16] Doshi et al (i) D.M. Suthar and A.V. Doshi, Mol. Cryst. Liq. Cryst. Vol. 575, PP. 76-83. (ii) H. N. Chauhan and A. V. Doshi, Mol. Cryst. Liq. Cryst. Vol. 570, PP. 92-100 (2013) (iii) R.P. Chaudhari, M.L. Chauhan and A.V Doshi, Vol. 575, PP. 88-95 (2013) (iv) U.C. Bhoya, N.N. Vyas and A.V. Doshi, Mol. Cryst. Liq. Cryst. Vol. 552. PP. 104-110. (2012).

[17] D. M. Suthar, A.A. Doshi and A.V. Doshi " Study of liquid crystalline state and evaluation of its properties through a novel homologous series", Mole. Cryst. Liq. Vol.582, PP.79-87, 2013.

[18] Upendra K. Jain, Rich K Bhatia, Akkinepally R. Rao, Ranjit Singh, Ajit K. Saxena and Irun Seha "Design and Development of halogenated Chalcone derivatives as potential cancer Agents” Tropical Journal of pharmaceutical Research, January 2014: 13 (1), 73-80.

[19] B.H. Patel and Doshi A.V (2015) ' Novel Cinnamate ester-Synthesis and Mesomorphic properties in relation to molecular structure' Molecular Crystal and Liquid crystals, 605, 4251. 
[20] Patel .B.H and Doshi A.V. " Synthesis and Mesomorphic Properties of a Novel Ester Homologous series: 4-(4'-n-Alkoxy Benzoyloxy) benzyl Cinnamates” Mol. Cryst. Liq. Cryst., Vol-606, PP.56-65. (2015)

[21] Patel B.H and Doshi A.V. "Dependence of Molecular Structure on Mesomorphic Behaviour with special Reference to Central Bridge" Mol. Cryst. and Liq. Cryst. Vol-608, PP. 38-46. (2015)

[22] Hird. M, Toyne. K. J, and Gray. G. W, Day S.E and Mc. Donell D.G (1993), Liq. Cryst. 15, PP.123.

[23] P.J. Collings and M. Hird (1997), Introduction of Liquid crystals chemistry and physics, Taylor and Francis Ltd. U.K. 1998.

[24] Marcos. M, Omenat. A, Serrano. J.L and Ezcurra. A (1992), Adv. Matter, 4, 285

[25] Hird. M, Toyne. K.J, Gray G.W., Day S.E. (1993) Liq. Cryst. 14, PP. 741.

[26] (a) Pieter-Ooms, Krefeld, Bernd-Ulrich Schenke, Bottrop, ' Process for the preparation of Hydroxybenzoic benzyl esters' United states of patent no: 2003/0053964 A1, Mar. 20, 2003. (b) European Patent EP0117502B1, Process of producing benzyl ester of aromatic hydrocarboxylic acid (Example-1), page 4, date of Publica. 19-11-1987.

[27] Rajesh.B. Marathe and Doshi A.V, Manuscript of a research paper entitled "Mesomorphism Dependance on Terminally Substituted End groups" accepted for publication to Mol. Crystal Liq. Crystal journal (Taylor and Francis) with its LCMH No.281, dated. 03.08.2014.

[28] Brijesh H. Patel and A.V Doshi, "Synthesis and liquid crystal properties of novel homologous series: 4-(4'-n-alkoxybenzyloxy) Benzyl benzoates' 'Molecular Crystals and Liquid crystals', 605:1, 61-69, 15.12.2015.

[29] Patel, B.H. and Doshi, A. V. (2015). Mol Cryst. Liq. Cryst., 607, 78-86

[30] Rajesh.B. Marathe and Doshi A.V, Manuscript of a research paper entitled "Mesomorphism Dependance on Molecular Rigidity with Reference to $-\mathrm{CH}=\mathrm{CH}$ - Unit of Central Bridge" accepted for publication to Mol. Crystal Liq. Crystal journal (Taylor and Francis) with its LCMH No.315. 